\title{
High-dose radiation associated with improved survival in IDH-wildtype low- grade glioma
}

\author{
Shuai Liư ${ }^{1,2}$, Yanwei Liu', Guanzhang Li ${ }^{2}$, Jin Feng ${ }^{1}$, Li Chen ${ }^{1}$ and Xiaoguang Qiu* ${ }^{* *}$
}

\begin{abstract}
Background: As molecular advances have deepened the knowledge on low-grade glioma (LGG), we investigated the effect of higher radiation dose on the survival of IDH-wildtype (IDHwt) LGG.

Methods: In the current study, 52 IDHwt LGG patients who received radiotherapy were enrolled from the Chinese Glioma Genome Atlas dataset. Radiation doses > 54 Gy were defined as high-dose, whereas doses $\leq 54$ Gy were defined as low-dose. We performed univariate and multivariate survival analyses to examine the prognostic role of high-dose radiotherapy.

Results: In total, the radiation dose ranged from $48.6 \mathrm{~Gy}$ to $61.2 \mathrm{~Gy}$, with a median of $55.8 \mathrm{~Gy}$, and 31 patients were grouped into high-dose radiation. Univariate survival analysis indicated that high-dose radiotherapy $(p=0.015)$, tumors located in the frontal lobe $(p=0.009)$, and pathology of astrocytoma $(p=0.037)$ were significantly prognostic factors for overall survival. In multivariate survival analysis, high-dose radiotherapy $(p=0.028)$ and tumors located in the frontal lobe $(p=0.016)$ were independently associated with better overall survival.

Conclusions: In conclusion, high-dose radiotherapy independently improved the survival of IDHwt LGG. This can guide treatments for glioma with known molecular characteristics.
\end{abstract}

Keywords: Radiation dose, IDH-wildtype, Low-grade glioma, Survival

\section{Background}

Low-grade glioma (LGG) is a highly heterogeneous group of gliomas, mainly including astrocytoma and oligodendroglioma. The survival of LGG varies significantly, with fortunate cases reaching more than 10 years. However, some cases, like glioblastoma, are shortened $[1,2]$. Since histopathological classification is insufficient to depict the biology of LGG, molecular advances play an important role. The 2016 World Health Organization classification of tumors of the central nervous system added molecular markers to histology in the

\footnotetext{
* Correspondence: qiuxiaoguang@bjtth.org

'Department of Radiation Oncology, Beijing Tiantan Hospital, Capital Medical University, Beijing 100070, China

Full list of author information is available at the end of the article
}

classification system of gliomas [3]. In particular, the status of isocitrate dehydrogenase (IDH) mutation and codeletion of chromosome arms $1 p$ and $19 q(1 p / 19 q$ codeletion) were identified biomarkers that yielded a more accurate diagnosis and prognosis for LGG.

Patients with IDH-wildtype (IDHwt) LGG had a significantly poor prognosis [1], and they benefitted from more aggressive treatments. Recent guidelines $[4,5]$ have identified IDH wildtype as a high-risk factor, and radiotherapy was suggested for these patients. However, the optimal radiation dose is still unclear. Two prospective clinical trials have revealed that increasing the radiation dose failed to prolong the survival of LGG patients [6, 7]. However, these results may be limited by the lack of molecular data. Since IDHwt is uncommon (less than

(c) The Author(s). 2021 Open Access This article is licensed under a Creative Commons Attribution 4.0 International License, which permits use, sharing, adaptation, distribution and reproduction in any medium or format, as long as you give appropriate credit to the original author(s) and the source, provide a link to the Creative Commons licence, and indicate if changes were made. The images or other third party material in this article are included in the article's Creative Commons licence, unless indicated otherwise in a credit line to the material. If material is not included in the article's Creative Commons licence and your intended use is not permitted by statutory regulation or exceeds the permitted use, you will need to obtain permission directly from the copyright holder. To view a copy of this licence, visit http://creativecommons.org/licenses/by/4.0/ The Creative Commons Public Domain Dedication waiver (http://creativecommons.org/publicdomain/zero/1.0/) applies to the data made available in this article, unless otherwise stated in a credit line to the data. 
$20 \%$ of all the LGGs $[2,8,9])$, there is still insufficient evidence on radiotherapy for this tumor.

In the current study, a cohort of IDHwt LGG was enrolled from the Chinese Glioma Genome Atlas (CGGA) dataset. Using univariate and multivariate survival analyses, we evaluated the prognostic role of radiation in IDHwt LGG. Our findings may improve the dismal prognosis of these tumors.

\section{Methods}

\section{Patients}

In the current study, 52 patients were enrolled from the CGGA dataset (http://www.cgga.org.cn). The inclusion criteria were (1) newly diagnosed, pathology-confirmed diffuse glioma (WHO II); (2) age > 18 years; (3) received radiotherapy; and (4) possessed IDH mutation, radiation dose, and survival data. The current study was approved by the Ethics Committee of Beijing Tiantan Hospital, and written informed consent was obtained from all participants.

\section{Clinical data}

Clinical information of all patients was obtained from the CGGA dataset. Age at diagnosis and preoperative Karnofsky Performance Status Scale (KPS) score were dichotomized as $>40$ or $\leq 40$ years, and as $\geq 70$ or $<70$, respectively. The extent of resection was evaluated by comparing the pre- and postoperative magnetic resonance images. Gross total resection (GTR) was defined as the removal of all abnormalities on T2/FLAIR-weighted images and failing to achieve GTR was defined as partial resection (< GTR). Seventeen (33\%) patients received chemotherapy with carmustine, nimustine, or temozolomide.

\section{IDH mutation detection}

The IDH1/2 mutation status was determined by the pyrosequencing method described in our previous work [10].

\section{Radiotherapy}

Most patients (41, 79\%) received 3D-conformal radiation therapy, and 11 patients received intensity-modulated radiation therapy (IMRT). A radiation dose $>54$ Gy was defined as high-dose while a dose $\leq 54$ Gy was defined as low-dose.

\section{Statistical analysis}

Clinical characteristics were compared via the Chisquare test.

Progression-free survival (PFS) was calculated from the date of surgery to the date of disease progression, or date last known to be progression-free. Overall survival (OS) was from the date of surgery to the date of death or last follow-up, whichever occurred first. To evaluate the prognostic role of radiation, the Kaplan-Meier method was used and compared by log-rank test. Cox proportional hazards regression (backward stepwise) was performed to identify independent risk factors for survival. Statistical analysis was performed using $\mathrm{R}$ language (https://www.r-project.org/), and a probability value $(p)$ $<0.05$ was considered significant. Missing values were excluded from statistical analysis.

\section{Results}

\section{Patient characteristics}

Among the 52 patients, 37 were male (71\%), and the median age was 42 years (range, 19-61 years). The median radiation dose was 55.8 Gy (range, 48.6. 61.2), and 31 patients were grouped into high-dose radiation. The comparison of clinical variables between the high- and low-dose radiation groups is shown in Table 1.

Table 1 Comparison of clinical characteristics

\begin{tabular}{|c|c|c|c|}
\hline Characteristics & High-dose (\%) & Low-dose (\%) & $P$ value $^{\mathrm{a}}$ \\
\hline Number & 31 & 21 & \\
\hline Age & & & 0.026 \\
\hline$>40$ & $14(47)$ & $16(53)$ & \\
\hline$\leq 40$ & $17(77)$ & $5(23)$ & \\
\hline Sex & & & 0.509 \\
\hline Male & $21(57)$ & $16(43)$ & \\
\hline Female & $10(67)$ & $5(33)$ & \\
\hline Location & & & 0.397 \\
\hline Frontal lobe & $17(65)$ & $9(35)$ & \\
\hline Other & $14(54)$ & $12(46)$ & \\
\hline \multicolumn{4}{|l|}{ Preoperative KPS $^{\mathrm{b}}$ score } \\
\hline$\geq 70$ & $31(60)$ & $21(40)$ & \\
\hline$<70$ & 0 & 0 & \\
\hline Histologic diagnosis & & & $0.458^{c}$ \\
\hline Astrocytoma & $13(54)$ & $11(46)$ & \\
\hline Oligodendroglioma & $4(67)$ & $2(33)$ & \\
\hline Oligoastrocytoma & $14(64)$ & $8(36)$ & \\
\hline Resection & & & 0.045 \\
\hline GTR & $16(76)$ & $5(24)$ & \\
\hline$<\mathrm{GTR}$ & $15(48)$ & $16(52)$ & \\
\hline Chemotherapy & & & 0.417 \\
\hline Yes & $9(53)$ & $8(47)$ & \\
\hline No & $22(65)$ & $12(35)$ & \\
\hline Missing & $0(0)$ & $1(100)$ & \\
\hline
\end{tabular}

${ }^{a}$ Chi-square test

${ }^{b}$ Karnofsky performance status scale

${ }^{c}$ Compared between astrocytoma and other LGG 


\section{Survival analysis}

In univariate survival analysis, tumors located in the frontal lobe $(p=0.010)$ and high-dose radiotherapy ( $p=$ 0.026) were significantly associated with better PFS. Meanwhile, pathology of astrocytoma $(p=0.005)$ and chemotherapy $(p=0.024)$ were associated with worse PFS. For OS, tumors located in the frontal lobe $(p=$ $0.009)$ and high-dose radiotherapy $(p=0.015)$ were significantly good prognostic factors, and pathology of astrocytoma ( $p=0.037)$ was still poor prognostic factor (Table 2$)$.

In multivariate survival analysis, GTR $(p=0.010)$ and pathology of astrocytoma $(p<0.001)$ were independently prognostic factors. Tumors located in the frontal lobe $(p$ $=0.016)$ and high-dose radiotherapy $(p=0.028)$ were independently associated with better OS (Table 3).

\section{PFS and OS in relationship to radiation dose}

The PFS and OS of patients treated with high-dose vs. low-dose are shown in Fig. 1a and b. The prognosis of the high-dose group was significantly better (PFS, $p=$ 0.022; OS, $p=0.010$ ).

\section{Discussion}

As molecular advances have improved the level of diagnosis and outcome prediction for LGG, treatment strategies need to be adjusted according to different molecular subtypes. This study aimed to determine the optimal radiation dose for IDHwt LGG. Survival analysis showed that high-dose radiotherapy independently prolonged patient survival. This finding may help tailor treatment strategies for IDHwt LGG.

The current multidisciplinary treatment strategies for glioma include surgery, radiotherapy, and chemotherapy. In recent decades, these treatments have been developed. Surgical techniques, including intraoperative electrical stimulations [11] and 5aminolevulinic acid [12] reportedly elevated resection rate. Chemotherapy regimens, such as PCV (procarbazine, lomustine, and vincristine) and temozolomide, significantly improved the survival of gliomas $[13,14]$. However, no novel treatment strategies have
Table 3 Multivariate analysis of survival outcomes $(n=52)$

\begin{tabular}{|c|c|c|c|}
\hline Characteristic & $p$ value & HR & $95 \% \mathrm{Cl}$ \\
\hline \multicolumn{4}{|c|}{ Progression-free survival } \\
\hline GTR & 0.010 & 0.259 & $0.092-0.728$ \\
\hline Astrocytoma & $<0.001$ & 6.936 & $2.465-19.516$ \\
\hline \multicolumn{4}{|l|}{ Overall survival } \\
\hline Frontal lobe & 0.016 & 0.274 & $0.096-0.782$ \\
\hline High-dose & 0.028 & 0.335 & $0.126-0.887$ \\
\hline
\end{tabular}

been proven effective for gliomas. Targeted therapy and immunotherapy have dramatically prolonged the survival of many tumors. For radiotherapy, the application of IMRT and proton therapy has significantly reduced the radiation dose to the surrounding brain tissue. This makes it possible for elevating dose to tumors much safer. However, the effect of higher doses of treatment for LGG patients is still unclear.

Several clinical trials have investigated whether highdose radiotherapy improved the prognosis of LGG. The EORTC study 22,844 included 379 LGG patients and randomized them between a low-dose arm of $45 \mathrm{~Gy}$ and high-dose arm of 59.4 Gy [6]. Meanwhile, the NCCTG study randomized 203 LGG patients between a low-dose arm of 50.4 Gy and high-dose arm of 64.8 Gy [7]. Both studies failed to conclude that LGG patients benefitted from high-dose radiotherapy. This negative result may be attributed to the heterogeneity of LGG, especially across the different molecular subgroups. As a most important biomarker, IDH mutation status deeply influences the pathophysiology of LGG, from survival to therapy response $[2,15]$. Tumors with IDH mutations, especially those accompanied by $1 \mathrm{p} / 19 \mathrm{q}$ codeletion, may be sensitive to radiotherapy. Thus, a lower dose is sufficient, and complications from higher doses may adversely induce worse prognosis. In contrast, IDHwt LGG is more aggressive, like glioblastoma, and resistant to radiotherapy. In this subgroup, we examined if highdose was a prognostic factor.

Since 45-54 Gy is the normal recommended dose for LGG [4], we declared doses > 54 Gy as high-dose.

Table 2 Univariate analysis of survival outcomes $(n=52)$

\begin{tabular}{|c|c|c|c|c|c|c|}
\hline \multirow[t]{2}{*}{ Characteristic } & \multicolumn{3}{|c|}{ Progression-free survival } & \multicolumn{3}{|c|}{ Overall survival } \\
\hline & $p$ value & HR & $95 \% \mathrm{Cl}$ & $p$ value & HR & $95 \% \mathrm{Cl}$ \\
\hline Age $>40$ & 0.080 & 2.215 & $0.909-5.400$ & 0.477 & 1.412 & $0.546-3.647$ \\
\hline Male & 0.379 & 0.679 & $0.287-1.609$ & 0.288 & 0.596 & $0.230-1.547$ \\
\hline Frontal lobe & 0.010 & 0.323 & $0.136-0.767$ & 0.009 & 0.254 & $0.090-0.714$ \\
\hline GTR & 0.152 & 0.505 & $0.199-1.284$ & 0.293 & 0.574 & $0.204-1.613$ \\
\hline Astrocytoma & 0.005 & 3.524 & $1.466-8.473$ & 0.037 & 2.781 & $1.062-7.279$ \\
\hline High-dose & 0.026 & 0.385 & $0.165-0.894$ & 0.015 & 0.306 & $0.119-0.793$ \\
\hline Chemotherapy & 0.024 & 2.651 & $1.134-6.194$ & 0.315 & 1.672 & $0.614-4.550$ \\
\hline
\end{tabular}

GTR gross total resection, $H R$ hazard ratio, $\mathrm{Cl}$ confidence interval 

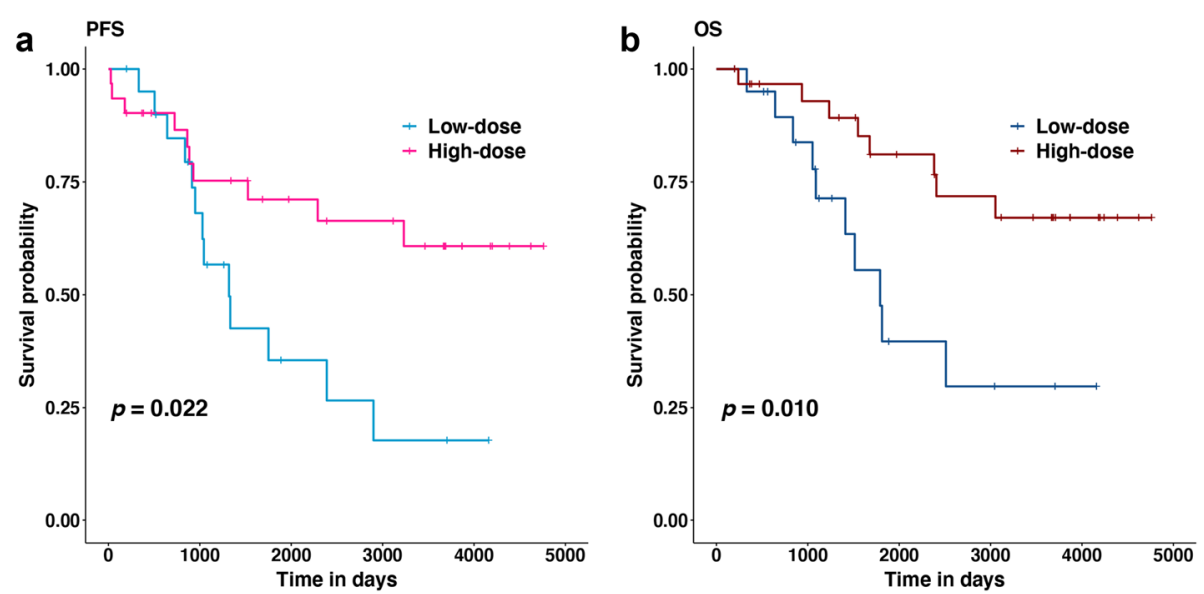

Fig. 1 Kaplan-Meier curves of comparison between high-dose and low-dose. a progression-free survival (PFS), b overall survival (OS)

Univariate and multivariate survival analyses found that high-dose radiotherapy was significantly associated with better survival in IDHwt LGG. For glioblastoma, the Stupp regimen is the standard treatment [14], and $60 \mathrm{~Gy}$ is recommended. In our cohort, 54.4-61.2 (median = 57.6) Gy was administered in the high-dose group. This dose range was deemed reasonable for IDHwt LGG. As cIMPACT-NOW update 3 pointed out that IDHwt LGG carried EGFR amplification, $+7 /-10$ or TERT promoter mutation was considered WHO grade IV [16]. A higher dose, closer to $60 \mathrm{~Gy}$, may bring more survival benefits for these patients.

\section{Limitations}

This study had limitations due to its retrospective nature. First, the radiation field was not evaluated for survival outcomes. Most patients receiving 3D field radiation may reduce bias between groups. Second, the specific chemotherapy regimen and courses for patients were unavailable.

\section{Conclusions}

This study found that high-dose radiotherapy independently improved the survival of IDHwt LGG. This can guide treatments for glioma with known molecular characteristics.

\section{Abbreviations}

CGGA: Chinese Glioma Genome Atlas; IDH: isocitrate dehydrogenase; IDHwt: IDH-wildtype; GTR: Gross total resection; LGG: low-grade glioma: OS: Overall survival; PFS: Progression-free survival

\section{Authors' contributions}

X.Q designed this study and revised the manuscript. S.L performed analysis and interpretation of data and drafted the manuscript. Y.L and G.L performed acquisition of survival and molecular data. J.F and L.C performed acquisition of radiation data. The authors read and approved the final manuscript.

\section{Funding}

This work was supported by The National Natural Science Foundation of China (Grant Numbers: 82001778), The Capital Medical Development Research Fund (Grant Numbers: 2020-2-1072).

\section{Availability of data and materials}

The datasets generated during and analyzed during the current study are available from the corresponding author on reasonable request.

\section{Declarations}

\section{Ethics approval and consent to participate}

The current study was approved by the Ethics Committee of Beijing Tiantan Hospital (KY2014-002-02).

Written informed consent was obtained from all participants.

\section{Consent for publication}

Not applicable.

\section{Competing interests}

The authors declare no potential conflict of interest.

\section{Author details}

'Department of Radiation Oncology, Beijing Tiantan Hospital, Capital Medical University, Beijing 100070, China. ${ }^{2}$ Department of Molecular Neuropathology, Beijing Neurosurgical Institute, Capital Medical University, Beijing 100070, China.

Received: 1 February 2021 Accepted: 11 March 2021

Published online: 01 April 2021

\section{References}

1. Eckel-Passow JE, Lachance DH, Molinaro AM, Walsh KM, Decker PA, Sicotte H, Pekmezci M, Rice T, Kosel ML, Smirnov IV, Sarkar G, Caron AA, Kollmeyer TM, Praska CE, Chada AR, Halder C, Hansen HM, McCoy LS, Bracci PM, Marshall R, Zheng S, Reis GF, Pico AR, O'Neill BP, Buckner JC, Giannini C, Huse JT, Perry A, Tihan T, Berger MS, Chang SM, Prados MD, Wiemels J, Wiencke JK, Wrensch MR, Jenkins RB. Glioma groups based on 1p/19q, IDH, and TERT promoter mutations in tumors. N Engl J Med. 2015;372(26):2499508. https://doi.org/10.1056/NEJMoa1407279.

2. Cancer Genome Atlas Research N, Brat DJ, Verhaak RG, Aldape KD, Yung WK, Salama SR, et al. Comprehensive, integrative genomic analysis of diffuse lower-grade gliomas. N Engl J Med. 2015;372(26):2481-98. https://doi.org/1 0.1056/NEJMoa1402121.

3. Louis DN, Perry A, Reifenberger G, von Deimling A, Figarella-Branger D, Cavenee WK, Ohgaki H, Wiestler OD, Kleihues P, Ellison DW. The 2016 World Health Organization Classification of Tumors of the Central Nervous System: a summary. Acta Neuropathol. 2016;131(6):803-20. https://doi.org/10.1007/ s00401-016-1545-1. 
4. Nabors LB, Portnow J, Ahluwalia M, et al. Central Nervous System Cancers, Version 3.2020, NCCN Clinical Practice Guidelines in Oncology[]], J Natl Compr Canc Netw. 2020;18(11):1537-70. https://doi.org/10.6004/jnccn.2020. 0052.

5. Jiang T, Mao Y, Ma W, Mao Q, You Y, Yang X, Jiang C, Kang C, Li X, Chen L, Qiu X, Wang W, Li W, Yao Y, Li S, Li S, Wu A, Sai K, Bai H, Li G, Chen B, Yao K, Wei X, Liu X, Zhang Z, Dai Y, Lv S, Wang L, Lin Z, Dong J, Xu G, Ma X, Cai J, Zhang W, Wang H, Chen L, Zhang C, Yang P, Yan W, Liu Z, Hu H, Chen J, Liu Y, Yang Y, Wang Z, Wang Z, Wang Y, You G, Han L, Bao Z, Liu Y, Wang Y, Fan X, Liu S, Liu X, Wang Y, Wang Q, Chinese Glioma Cooperative Group (CGCG). CGCG clinical practice guidelines for the management of adult diffuse gliomas. Cancer letters. 2016;375(2):263-73. https://doi.org/10.1016/j. canlet.2016.01.024.

6. Karim AB, Maat B, Hatlevoll R, Menten J, Rutten EH, Thomas DG, et al. A randomized trial on dose-response in radiation therapy of low-grade cerebral glioma: European Organization for Research and Treatment of Cancer (EORTC) Study 22844. Int J Radiat Oncol Biol Phys. 1996;36(3):549-56. https://doi.org/10.1016/s0360-3016(96)00352-5.

7. Shaw E, Arusell R, Scheithauer B, O'fallon J, O'neill B, Dinapoli R, et al. Prospective randomized trial of low-versus high-dose radiation therapy in adults with supratentorial low-grade glioma: initial report of a North Central Cancer Treatment Group/Radiation Therapy Oncology Group/Eastern Cooperative Oncology Group study. J Clin Oncol. 2002;20(9):2267-76. https://doi.org/10.1200/JCO.2002.09.126.

8. Yan H, Parsons DW, Jin G, McLendon R, Rasheed BA, Yuan W, Kos I, BatinicHaberle I, Jones S, Riggins GJ, Friedman H, Friedman A, Reardon D, Herndon J, Kinzler KW, Velculescu VE, Vogelstein B, Bigner DD. IDH1 and IDH2 mutations in gliomas. N Engl J Med. 2009;360(8):765-73. https://doi.org/10.1 056/NEJMoa0808710.

9. Yang P, Cai J, Yan W, Zhang W, Wang Y, Chen B, Li G, Li S, Wu C, Yao K, Li W, Peng X, You Y, Chen L, Jiang C, Qiu X, Jiang T, CGGA project. Classification based on mutations of TERT promoter and IDH characterizes subtypes in grade II/III gliomas. Neuro-oncology. 2016;18(8):1099-108. https://doi.org/10.1093/neuonc/now021.

10. Yan W, Zhang W, You G, Bao Z, Wang Y, Liu Y, Kang C, You Y, Wang L, Jiang T. Correlation of IDH1 mutation with clinicopathologic factors and prognosis in primary glioblastoma: a report of 118 patients from China. PLoS One. 2012;7(1):e30339. https://doi.org/10.1371/journal.pone.0030339.

11. Duffau H, Lopes M, Arthuis F, Bitar A, Sichez J, Van Effenterre R, et al. Contribution of intraoperative electrical stimulations in surgery of low grade gliomas: a comparative study between two series without (1985-96) and with (1996-2003) functional mapping in the same institution. J Neurol Neurosurg Psychiatry. 2005;76(6):845-51. https://doi.org/10.1136/jnnp.2004. 048520.

12. Stummer W, Reulen HJ, Novotny A, Steppe H, Tonn JC. Fluorescenceguided resections of malignant gliomas - an overview. In: Westphal $\mathrm{M}$, Tonn JC, Ram Z. (eds) Local Therapies for Glioma Present Status and Future Developments. Acta Neurochirurgica Supplements. 2003;88:9-12. Vienna: Springer. https://doi.org/10.1007/978-3-7091-6090-9_3.

13. Shaw EG, Wang M, Coons SW, et al. Randomized trial of radiation therapy plus procarbazine, lomustine, and vincristine chemotherapy for supratentorial adult low-grade glioma: initial results of RTOG 9802[J]. J Clin Oncol. 2012;30(25):3065.

14. Stupp R, Mason WP, Van Den Bent MJ, Weller M, Fisher B, Taphoorn MJ, et al. Radiotherapy plus concomitant and adjuvant temozolomide for glioblastoma. N Engl J Med. 2005;352(10):987-96. https://doi.org/10.1056/ NEJMoa043330.

15. Bell EH, Zhang P, Shaw EG, Buckner JC, Barger GR, Bullard DE, Mehta MP, Gilbert MR, Brown PD, Stelzer K, McElroy JP, Fleming J, Timmers CD, Becker AP, Salavaggione AL, Liu Z, Aldape K, Brachman DG, Gertler SZ, Murtha AD, Schultz CJ, Johnson D, Laack NN, Hunter GK, Crocker IR, Won M, Chakravarti A. Comprehensive genomic analysis in NRG oncology/RTOG 9802: a phase III trial of radiation versus radiation plus procarbazine, lomustine (CCNU), and vincristine in high-risk low-grade glioma. J Clin Oncol. 2020;38(29): 3407-17. https://doi.org/10.1200/JCO.19.02983.

16. Brat DJ, Aldape K, Colman H, Holland EC, Louis DN, Jenkins RB, Kleinschmidt-DeMasters BK, Perry A, Reifenberger G, Stupp R, von Deimling A, Weller M. cIMPACT-NOW update 3: recommended diagnostic criteria for "Diffuse astrocytic glioma, IDH-wildtype, with molecular features of glioblastoma, WHO grade IV". Acta Neuropathol. 2018;136(5):805-10. https:// doi.org/10.1007/s00401-018-1913-0.

\section{Ready to submit your research? Choose BMC and benefit from:}

- fast, convenient online submission

- thorough peer review by experienced researchers in your field

- rapid publication on acceptance

- support for research data, including large and complex data types

- gold Open Access which fosters wider collaboration and increased citations

- maximum visibility for your research: over $100 \mathrm{M}$ website views per year

At $\mathrm{BMC}$, research is always in progress.

Learn more biomedcentral.com/submissions 